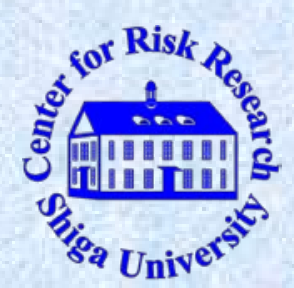

CRR DISCUSSION PAPER SERIES A

Discussion Paper No. A-31

Daniel Ellsberg on J.M. Keynes and F.H. Knight:

Risk, Ambiguity and Uncertainty

Yasuhiro Sakai

June 2018

Center for Risk Research

Faculty of Economics

SHIGA UNIVERSITY

1-1-1 BANBA, HIKONE,

SHIGA 522-8522, JAPAN 


\title{
Daniel Ellsberg on J.M. Keynes and F.H. Knight:
}

\author{
Risk, Ambiguity and Uncertainty * \\ Yasuhiro Sakai \\ Professor Emeritus, Shiga University
}

\begin{abstract}
This paper aims to focus on the life and work of Daniel Ellsberg, with an intensive discussion on its relation to J.M. Keynes and F.H. Knight, the two great pioneers of the economics of uncertainty. Ellsberg seems to be a man in paradox. When he was young, he was an outstanding researcher at Harvard University and the RAND Corporation; at the December Meting of the Econometric Society in 1960, he presented his remarkable paper in which he successfully demonstrated what we may now call Ellsberg's paradox against the traditional expected theory a la Daniel Bernoulli and von Neumann. Although it was published with the title "Risk, ambiguity and decision" in the November issue of the Quarterly Journal of Economics, it was not paid due attention for a long time. It was partly because he was so preoccupied in the 1960s and onward by letting the general public know the Pentagon papers that he could virtually have no time left to engage in purely academic activities. In the 21st century, however, the times have changed in favor of Ellsberg: we can see the dramatic return of interest in decision making under ambiguity.

Chapter II will deal with uncertainties that are not risks. A focal point of discussion will be the similarity and difference between Keynes and Knight. Kenneth Arrow's skepticism about Knight on uncertainty will also be paid due attention. Chapter III, the main part of this paper, will turn to the concept of ambiguity that was first introduced by Ellsberg. The two-color problem and the three color problem will systematically be examined by help of numerical representations. Chapter IV will tell us many alternative ways to solve the so-called Ellsberg paradox. Presumably, the Keynesian approach by means of interval-valued probabilities will be shown to be very simple and highly effective. In our opinion, the most amazing Ellsberg paradox lies in the fact that an accomplished economist specialized in the aversion of risk and uncertainty dared to make a personal choice to risk everything such as degrading his social status and putting him in prison for a long period. Surely, the intellectual legacy of Ellsberg seems to be an intriguing research in paradox.
\end{abstract}

Keywords Ellsberg, Keynes, Knight, risk, ambiguity, uncertainty

JEL Classification B21, B22, D81, E12 


\section{Introduction}

The main purpose of this paper is to focus on Daniel Ellsberg with an intensive discussion on how his life and work are related to his two predecessors, J.M. Keynes and F.H. Knight. It is in 1921 that Keynes and Knight published apparently similar books on the economics of risk and uncertainty (see Keynes (1921), Knight (1921)). Forty years later, Ellsberg (1961) published an important article on risk and ambiguity in the Quarterly Journal of Economics. Interestingly enough, in the following year of 1962, he completed his Ph.D. thesis in economics. Although this thesis, entitled Risk, Ambiguity and Decision, was a masterpiece, it remained nevertheless unaddressed for long in the academic world: in fact, only in 2001, it suddenly came out as an academic book and has been available to the general public since then. The long span between 1961 and 2001 may eloquently tell us his own turbulent years as the mastermind of the "Pentagon Papers" scandal in the 1970s and after: he was once called "the most dangerous man in America." It seems, however, that Ellsberg might live twice like the "007" in the popular spy movies. At present, his academic influence on the economics of risk and uncertainty is certainly stronger than ever before. So we believe that it is quite worthwhile to look closely into his life and work in special relation to Keynes and Knight

In retrospect, Ellsberg seems to be a man in paradox. Although in 1952, he graduated in economics at Harvard University, a top academic institution in the U.S., he dared to leave it immediately after graduation to serve a US Marine. In 1957, however, he came back to Harvard for his graduate studies, starting to work on decision making under uncertainty, a new challenging field of investigation. During his graduate studies, he left Harvard again to join the RAND Corporation as a strategic analyst. In spite of his occupational status as a "practical man," he never gave up to pursue his academic career, and at the December Meeting of the Econometric Society in St. Louis in 1960, he presented his remarkable paper in which he successfully demonstrated what we may now call the Ellsberg paradox against the standard expected utility theory. Fortunately, it was published as part of a symposium on "Decision under Uncertainty" in November 1961 issue of the Quarterly Journal of Economics, a first-rate academic journal. Unfortunately, however, the issue per se was not paid a due attention for a long time. While one year later, namely in 1962, he completed his thesis with an attractive title Risk, Ambiguity and Decision, it became almost forgotten until its publication as an academic book in 2001, almost 40 years later. 
Of course, there must be the reason for such overdue return of the master! In fact, he was a man of strong will and justice, being so preoccupied by letting the general public know the Pentagon papers that he could virtually have no time left to participate in purely academic discussions. In his provocative book (2002), he remarked:

\footnotetext{
"So the question was, how could I now help to end this war [the Vietnam War], now that I was willing to go to prison. And within a few weeks the idea came to me of putting out the pentagon papers, which I thought put me to prison for the rest of my life." (Ellsberg, 2002)
}

It is true that Ellsberg contributed to decision science by introducing the Ellsberg paradox into the academic profession. The more amazing Ellsberg paradox, however, lies in the fact that an accomplished economist specialized in the aversion of risk and uncertainty dared to make a personal choice to risk everything such as degrading his social status and putting him in prison for a long period. Surely, the intellectual legacy of Ellsberg seems to be an intriguing research in paradox. 1)

The remainder of this paper is organized as follows. Chapter II will deal with uncertainties that are not risks. A focal point of discussion will be the similarity and difference between Keynes and Knight. Kenneth Arrow's skepticism about Knight on uncertainty will also be paid due attention. Chapter III, the main part of this paper, will turn to the concept of ambiguity that was first introduced by Ellsberg. The two-color problem and the three color problem will systematically be examined by help of numerical representations. Chapter IV will tell us many alternative ways to solve the so-called Ellsberg paradox. Presumably, the Keynesian approach by means of interval-valued probabilities will be shown to be very simple and highly effective. Chapter $\mathrm{V}$ will make some final remarks.

\section{Uncertainties That Are Not Risks}

\section{2-1. Keynes and Knight: Their Similar yet Different Views}

In the light of the history of economic thought, J.M. Keynes and F.H. Knight stand out as the two superstars who have bravely introduced the concept of uncertainty into the main body of economic science and effectively demonstrated that uncertainty should categorically be different from risk. Let us briefly review their similar yet different views on risk and uncertainty. 2)

According to Robert Skidelsky, a famous biographer of J.M. Keynes, we have been living through one of the most drastic irregularities and collapses in the last one 
hundred years. Our economic profession, however, has done "an exceptionally poor job in explaining it" (see Skidelsky (2009), Introduction, page xv). We have virtually little idea about how to stop a succession of economic depressions which might bear down on us for so many decades to come. So Skidelsky concludes that it is high time to get back to J.M. Keynes, the economic master of the twentieth century. 3)

Keynes is the economist who takes uncertainty very seriously: the centerpiece of Keynes's theory is the existence of unavoidable uncertainty about the future. In a follow-up paper (1937) just after his main work (1936), he made his position on uncertainty quite clear:

\footnotetext{
By 'uncertain' knowledge, let me explain, I do not mean merely to distinguish what is known for certain from what is only probable. The game of roulette is not subject, in this sense, to uncertainty; nor is the prospect of a Victory bond being drawn. Or, again, the expectation of life is only slightly uncertain. Even the weather is moderately uncertain. The sense in which I am using the term is that in which the prospect of a European war is uncertain, or the price of copper and the rate of interest twenty years later hence, or the obsolescence of a new invention, or the position of private wealth owners in the social system in 1970. About these matters, there is no scientific basis on which to form any calculable probability whatever. We simply do not know". (Keynes, 1937, pp. 209-223)
}

Keynes makes a clear-cut distinction between risk and uncertainty. Risk can be described by a certain form of probability distribution. For an example, in regard to the game of roulette, the probability of winning or losing must be calculated in advance. For another, the life expectancy of Japanese female 60 years old as of 2017 is also calculable. In contrast to risk, uncertain events might take place all of a sudden: therefore, there should be no scientific basis on which to form any calculable probability at all. Presumably, unexpected events carrying huge impact, which is cleverly called "Black Swans" by Taleb (2007), might take place at any place at any time.

According to Keynes's observation, people are not only guided by mere pecuniary motives, they are also guided by more effective animal spirits or non-economic motivations. In this connection, Keynes (1936) eloquently remarked:

\footnotetext{
"We are merely reminding ourselves that human decisions affecting the future, whether personal or political or economic, cannot depend on strict mathematical expectations, since the basis for making such calculations does not exist; and that it is our innate urge to activity which makes the wheels go around, our rational selves choosing between the alternatives
} 
as best we are able, calculating where we can, but often falling back for our motive on whim or sentiment or chance." (Keynes, 1936, pp.162-163)

Keynes is a "practical man" with many faces. He spent a very colorful life throughout his career, first as a university instructor, then as a government officer and as a business man, and sometimes as an art collector. He does not believe that human decisions cannot always depend strict mathematical calculations such as expected utility maximization. We often fall back for our motive on psychological factors including whim, sentiment, chance and the like. We would like to say that the practical side of Keynes was somehow followed by Ellsberg, who left a prestigious university to get a practical job at the Rand corporation and was involved in the political "Pentagon papers scandal" and a series of legal fights in court.

In their recent collaboration, G. A. Akerlof and R.J. Shiller (2009) have reminded us of the central position occupied by animal spirits in the economics of Keynes.

Keynes (1936) once remarked:

\footnotetext{
"[T]here is the instability due to the characteristic of human nature that a large proportion of our positive activities depend on spontaneous optimism rather than on a mathematical expectation, whether moral or hedonistic or economic. Most, probably, of our decisions to do something positive, the full consequences of which will be drawn out over many days to come, can only be taken as a result of animal spirits - of a spontaneous urge to action rather than inaction, and not as the outcome of a weighted average of quantitative benefits multiplied by quantitative probabilities." (Keynes, 1936, p. 161)
}

Keynes has repeatedly stressed that if such animal spirits are dimmed and the spontaneous optimism falters and leave us depend on a mere mathematical expectation, then capitalist enterprises will fade and eventually die. According to Akerlof and Shiller (2009), the concept of animal spirits is not the forgotten lesson of the 1930s: it is still alive in the 2000s and even more lively in the 2010s. There are not a few people who optimistically believe that the Great Depression is merely the past tragedy of the 20th century. We must bear in mind, however, that a repeat of the Great Depression is now a possibility since economists, the government, and the general public have in recent years grown more complacent than ever. As the saying goes, power will collapse, and absolute power will collapse absolutely! Likewise, over-expectation is destined to be self-destructive and will eventually collapse overly!

While Keynes was born with a silver spoon at Cambridge in the traditional British 
Empire, Knight was born with a wooden spoon in the countryside in the new superpower, namely the United States. Although their birth places were quite apart, they could be regarded as contemporaries; strictly speaking, Knight was only two years younger than Keynes. Knight's novel idea of uncertainty is clearly seen in the following sentence:

\begin{abstract}
"Uncertainty must be taken in a sense radically distinct from the familiar notion of Risk, from which it has never been properly separated. ..... It will appear that a measurable uncertainty, or 'risk' proper, as we shall use the term, is so far different from an unmeasurable one that it is not in effect an uncertainty at all. We shall accordingly restrict the term 'uncertainty' to cases of the non-quantitative type. It is this 'true' uncertainty, and not risk, as has been argued, which forms the basis of a valid theory of profit and accounts for the divergence between actual and theoretical competition." (Knight, 1921, pp. 19-20)
\end{abstract}

The book of uncertainty written by Knight is one of the 20th century's monumental book, firmly providing the theoretical basis of the market economy. Since the first edition published in 1921 just after the First World War, the re-issue with a long preface came out during the Great Depression in 1933, a reprint edition and another reprint one respectively followed in 1948 and in 1956 after the Second World War. Knight is a hard-boiled researcher, thereby persistently maintaining his original position on the role of uncertainty as distinct from risk during his long career. In fact, in the Preface for the Reprint of 1948, he remarked:

\footnotetext{
"No more elaborate theory of uncertainty would be offered. It is still my conviction that contingency or 'chance' is an un-analyzable fact of nature. ... Chance is more than human ignorance of causality which is 'really' absolute. No perfect probability class can be known as such. Perfect randomness cannot be defined, or its relation to 'err' stated-nor to 'freedom," (Knight, 1957 edition, Preface, page lxiii)
}

In spite of the fact that Knight and Keynes appeared to deal with very similar topics such as uncertainty and decision, their positions on the role of economic science looked considerably apart, and sometimes even antagonistic. In particular, Knight did not agree with Keynesian way of macroeconomic and monetary thinking. In his methodological paper on the role of principles in economics and politics, Knight (1951) criticized Keynes in very harsh words: 
"The latest 'new economics,' and in my opinion rather the worst for fallacious doctrine and pernicious consequences, is that launched by the late John Maynard (Lord) Keynes, who for a decade succeeded in carrying economic thinking well back to the dark age, but of late this wave of the future has happily been passing." (Knight, 1951;contained in Selected Essays, Vol. 1, pp.362-363.)

As the saying goes, dead men tell no tales. It must have been a sort of shocking surprise to the general public that in his presidential address delivered at the 63rd Annual Meeting at the American Economic Association, Chicago, December 25, 1950, Knight attacked the work of the late Keynes in a very ungentlemanly manner. We believe that if Keynes had been alive in 1951, he would surely have wanted to tell something. In retrospect, it would be grossly unfair to say that Keynes carried economic thinking well back to the dark age. More fairly speaking, Keynesian uncertainty is macro-oriented and Knightian uncertainty is micro-oriented. Macro is macro, and micro is micro. To some fundamentals such as Knight, these two would never meet together. There are a group of more open-minded persons including the present author, however, who would say that macro and micro can stand together, implying that Keynesian and Knightian uncertainties are reconcilable. The question of integration of the two approaches, Keynesian and Knightian approaches, remains very important even today, requiring a further investigation in the future.

\section{2-2. Arrow's Skepticism about Knight on Uncertainty}

Kenneth J. Arrow is no doubt a superstar along with Paul A. Samuelson; their contributions to theoretical and welfare economics have been too vast and deep to be properly measured. It is this great Arrow who had serious doubts about Knight's distinction between risk and uncertainty. For instance, in one of his influential papers in Econometrica, Arrow (1951) once remarked:

Knight denies that all types of risks can be described by probability statements. Knight's uncertainties seem to have surprisingly many of the properties of ordinary probabilities, and it is no clear how much is gained by the distinction." (Arrow, 1951; contained in Arrow, 1970, pp. 17-18)

Fairly speaking, Arrow was well-known as an open-minded and generous gentleman. So his uncharacteristic skepticism about Knight's distinction between risk and uncertainty must have been a shocking news to many economists. As mentioned 
above, Knight's fundamental position was that risk was measurable in the sense that it was describable by a certain distribution function but uncertainty was definitely not so. Therefore, Arrow shared the superficial view that Knightian uncertainties seemed to have so many properties of ordinary probabilities that the possible gain obtained by the distinction between risk and uncertainty was minimum. Here we can see the existence of a big gap between Knight and Arrow, which is the important point that has not been rather neglected in the literature.

In his characteristic fashion, Knight stubbornly defended his view in favor of uncertainty throughout his career. Let us remind of Knight's classification viewpoint by which there different types of probability situations should clearly be separated. First, we can argue a priori probability that is just logical or mathematical as can be exemplified by the probability of throwing a dice for "six", namely the fraction 1/6. Second, we may refer to statistical probability such as the life expectancy of a person at a given point of time. These two probabilities are apparently measurable, thus being indicated by a certain probability distribution. Knight proceeds to point out the third and new type of probability, especially referred to estimates, which is neither mathematical nor empirical. Let us take a close look at the following sentence:

\footnotetext{
"The distinction here is that there is no solid basis of any kind for classifying instances. This form of probability is involved in the greatest logical difficulties of all, and no very satisfactory discussion of it can be given, but its distinction from the other types must be emphasized and some of its complicated relations indicated." (Knight, 1921, p. 225)
}

Knight argues that estimates or judgments are liable to err, although the other two types of probability are completely free from any human mistakes. There should be no basis whatever of comparison for determining the probability of error in a judgment. He takes as an illustration a typical business decision. He eloquently continues his argument:

\footnotetext{
"The business man himself not merely forms the best estimate he can of the outcome of his action, but he is likely also to estimate the probability that his estimate is correct. The 'degree' of certainty or of confidence felt in the conclusion after it is reached cannot be ignored. for it is of the greatest practical significance. The action which follows upon an opinion depends as much upon the amount of confidence in that opinion as it does upon the favorableness of the opinion itself. The ultimate logic, or psychology, of these deliberations is obscure, a part of the scientifically unfathomable mystery of life and mind. We must simply fall back upon a 'capacity'
} 
in the intelligent animal to form more or less correct judgments about things, an intuitive sense of values. " (Knight , 1921, page 227)

No doubt, the quotation aforementioned seems a bit too long. We do believe, however, that it deserves to do so. Knight emphasizes that the ultimate logic, or the psychology, of human action tends to be obscure, demonstrating a part of the scientifically unfathomable mystery of life and mind. We are no longer a scientifically logical super-machine, but rather the mere intelligent animal that is sometimes involved in the unfathomable mystery of life and mind. Presumably, it is in this psychological and even mysterious aspect of human life and mind that Arrow has mentioned his strong skepticism about Knight's view of uncertainty. In a sense, Knight is a philosophical man who takes account of non-reasonable aspect of human mind and behavior, whereas Arrow is a very reasonable man who tends to balance the cost and benefit of his action, thus under-evaluating the effect of psychology on economic behavior. Knight is very much concerned with following out the consequences of such higher form of uncertainty not susceptible to measurement. "It is this true uncertainty which by preventing the theoretically perfect outworking of the tendencies of competition gives the characteristic form of 'enterprise' to economic organization as a whole and accounts for the peculiar income of the entrepreneur." (Knight, 1921, page. 232) Then he argues that the presence of true profit depends on true uncertainty in the estimation of the value of judgment. ${ }^{4)}$

All in all, the existence and persistence of non-measurable uncertainty forms the core of the economic theory of Knight. Arrow's skepticism about Knight's concept of uncertainty cannot be accepted by Frank Knight and his followers. 5)

\section{Ambiguity and Risk}

\section{3 -1. Keynes on the "Two-Color Urn" Problem}

It is said that forty years after the Pentagon Papers scandal, Daniel Ellsberg remains a revel with a cause. Although Ellsberg has usually been associated with the historical scandal, we nevertheless must remember that he was once a first-rate researcher working for Harvard University and later for the Rand Corporation, and that his academic prestige has come back rather quickly since academic interest in decision under ambiguity has gained a momentum in recent years.

As Levi (2001) lucidly explained, Daniel Ellsberg courageously challenged the traditional theory of rational decision based on the expected-utility rule a la Bernoulli (1738). Ellsberg submitted his doctoral dissertation to the Economics Department of 
Harvard University in April 1962, within a year after he had published a highly academic paper "Risk, ambiguity, and the Savage axioms" in the Quarterly Journal of Economics. While the 1961 paper was a first-rate paper on decision making under ambiguity, it was perhaps too academic to receive proper hearing. Besides, his dissertation had not been noticed for a long time as if it had been put in the black box. And eventually, it reappeared in the publishing circles in 2001 after nearly forty sleeping years.

We would like to point out the fact that there has been a noticeable gap between the 1961 paper and the 1962 dissertation with respect to the place of Keynes and Knight in the world of Ellsberg. It would be quite worthwhile to fill in such a neglected gap so that we could more systematically discuss the relations among those three superstars, namely, Keynes, Knight and Ellsberg.

As sharply pointed out by Zappla (2016) in quite recent times, it was the great Keynes himself who placed emphasis on the idea that in situations where information was not so clear and rather vague, the traditional approach a la Bernoulli was zoomed to invalidity. It was a shocking truth that Ellsberg failed to refer to Keynes in the 1961 paper, but showed much respect to Keynes in the 1962 dissertation. Presumably, such non-symmetrical treatment of Keynes by Ellsberg seemed to be mysterious to every conscientious reader.

As the saying goes, seeing is believing. Let us faithfully record the two-color urn problem originally provided by Keynes (1921):

\footnotetext{
"The typical case, in which there may be a practical connection between weight and probable error, may be illustrated by the two cases following of balls drawn from an urn. In each case we require the probability of a white ball; in the fist case we know that the urn contains black and white in equal proportions; in the second case the proportion of each color is unknown, and each ball is as likely to be black as white. It is evident that in either case the probability of drawing a white ball is $1 / 2$, but that the weight of the argument in favor of this conclusion is grater in the first case." (Keynes, 1921, pp. 75-76)
}

The importance of the urn problem given by Keynes (1921) cannot be overstated since it represents a pioneering study on the new concept of ambiguity. We think that it is remarkable because of the following two reasons. First, it was presented and analyzed well ahead of Daniel Ellsberg (1961). Second, strangely enough, it was never referred to by Ellsberg. We believe that Ellsberg might have just overlooked it. Its graphical explanation is provided in Fig. 1. There are two cases to consider. In Case 
We draw balls from an urn. Then find the probability of drawing a white ball.

Case I (Bet on B): We know that the urn contains black (B) and white (W)

in equal proportions.

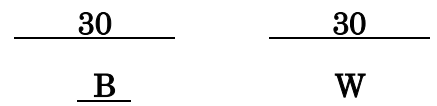

Case II (Bet on B): The proportion of each color is unknown.

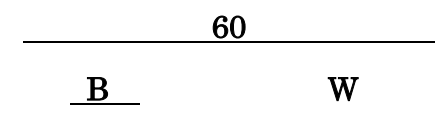

Keynes argues that the weight of the argument in favor of drawing $\mathrm{W}$ is greater in the first case than in the second case. Ellsberg would rather say that people prefer the numerically clear case I to the vague case II .

Fig. 1 Keynes on the urn problem: a pioneering study of ambiguity

I , the urn is supposed to contain black (B) and White (W) in equal proportions, namely 50-50 \%. In Case II, the proportion of $\mathrm{B}$ or $\mathrm{W}$ is quite ambiguous or totally unknown. We assume that in each case we bet on $\mathrm{B}$ to be underlined in the figure.

Clearly, this is a typical decision problem under ambiguity. Keynes himself has given the interpretation that the weight of the argument in favor of drawing $\mathrm{W}$ is greater in Case I than in Case II. Alternatively, Ellsberg would rather say that people prefer the numerically clear case I to the vague case II. In other words, in terms of modern terminology, we would say that the person who bets on B shows ambiguity aversion.

This two-color urn example tells us that the standard expected utility rule originated by Bernoulli is no longer valid. In fact, if we took advantage of the expected utility rule, the expected utilities of Cases I and II could have led us to the same quantity as shown below:

$$
\mathrm{EU}(\mathrm{I})=\mathrm{EU}(\mathrm{II})=(1 / 2) \mathrm{U}(\mathrm{B})+(1 / 2) \mathrm{U}(\mathrm{W})
$$

It is recalled here that the indifference principle a la Keynes (1921) is adopted here, meaning that unknown proportions of each color can positively be interpreted as equal proportions, namely half -and-half. 


\section{3-2. Ellsberg on the "Three-Color Urn" problem}

We are now in a position to carefully discuss the three-color urn problem originated in Ellsberg (1961, 1962). It is worth mentioning that the 1961 paper by Ellsberg began with the following conspicuous sentence:

\footnotetext{
"There are always been a good deal of skepticism about the behavioral significance of Frank

Knight's distinction between 'measurable uncertainty' or 'risk,' which may be represented by numerical probabilities, and 'unmeasurable uncertainty' which cannot." (Ellsberg, 1961, p.643)
}

When Ellsberg was an active researcher in the 1960s, there was a good deal of skepticism about Knight's distinction between measurable risk and non-measurable uncertainty. Among those skeptical papers were Arrow's 1951 paper aforementioned. It was the young Ellsberg who intended to wipe out such unfair accusation against Knight and wanted to seriously discuss those uncertain prospects which are not risks. In so doing, he cleverly introduced the new concept "ambiguity" in his analytical framework. As will be seen below, ambiguity is neither ordinary risk nor wide-ranging uncertainty: it is an ingenious concept put somewhere between risk and uncertainty.

Seeing is believing! Let us revaluate Ellsberg's new approach to decision under ambiguity by means of a set of numerical illustrations. In particular, he considers the "three-color urn" problem which seems to be a masterly extension of Keynes's "two-color urn" problem to the three-color case. Take a close look at Fig. 2. Let us imagine an urn known to contain 30 red (R) balls and 60 black (B) and yellow (Y) balls, the latter in unknown proportions. One ball is to be drawn at random from the urn. First , compare a pair of gambles; Gamble I (Bet on R) and Gamble II (Bet on B). The question to ask is which gamble people prefer, Gamble I or II. Next, consider another pair of gambles; Gamble III (Bet on R or Y) and Gamble IV (Bet B or Y). According to Ellsberg's experiments, a very frequent pattern of response is as follows: Gamble I is preferred to II, but IV preferred to III.

The question is why such preference reversal occurs. People prefer I to II because they find the sure prize of $\$ 100$ (with winning probability $1 / 3$ ) more attractive than the ambiguous prize ranging from $\$ 0$ to $\$ 100$ (with winning probability $2 / 3$ ). But they prefer IV to III since they feel the sure prize of $\$ 100$ (with winning probability 2/3) more appealing to the ambiguous prize (with winning probability widely ranging from $1 / 3$ to 1 ). In either choice, people indicates their preference for the sure prize over the ambiguous prize, demonstrating their attitude to ambiguity aversion. 


\begin{tabular}{|c|c|c|c|}
\hline & 30 & \multicolumn{2}{|c|}{60} \\
\hline & Red (R) & Black (B) & Yellow (Y) \\
\hline Gamble I (Bet on R): & $\$ 100$ & $\$ 0$ & $\$ 0$ \\
\hline \multirow[t]{3}{*}{ Gamble II (Bet on B): } & $\$ 0$ & $\$ 100$ & $\$ 0$ \\
\hline & 30 & \multicolumn{2}{|c|}{60} \\
\hline & $\operatorname{Red}(\mathrm{R})$ & Black (B) & Yellow (Y) \\
\hline Gamble III (Bet on R or Y): & $\$ 100$ & $\$ 0$ & $\$ 100$ \\
\hline Gamble IV (Bet on B or Y): & $\$ 0$ & $\$ 100$ & $\$ 100$ \\
\hline
\end{tabular}

Fig. 2 Ellsberg's paradox : most people prefer Gamble I to II, but IV to III.

Those examples shown in Fig. 2 will teach us that the standard expected utility principle is no longer valid here. In fact, if we apply the expected utility theory, the expected utility of Gamble I is calculated as follows:

$$
\mathrm{EU}(\mathrm{I})=\operatorname{Prob}(\mathrm{R}) \mathrm{U}(100)+\operatorname{Prob}(\mathrm{B}) \mathrm{U}(0)+\operatorname{Prob}(\mathrm{Y}) \mathrm{U}(0) .
$$

Now if we assume that $\operatorname{Prob}(\mathrm{B})=\rho$, we immediately have $\operatorname{Prob}(\mathrm{Y})=1^{-} \rho$. Then Eq. (2) can be rewritten as follows:

$$
\mathrm{EU}(\mathrm{I})=(1 / 3) \mathrm{U}(100)+(\rho) \mathrm{U}(0)+\left(1^{-} \rho\right) \mathrm{U}(0) .
$$

Without loss of generality, we can suppose that $\mathrm{U}(100)=1$ and $\mathrm{U}(0)=0$, a sort of normalization procedure. Then Eq. (3) is further simplified as follows:

$$
\mathrm{EU}(\mathrm{I})=(1 / 3)(1)+(\rho)(0)+\left(1^{-} \rho\right)(0)=1 / 3
$$

In a similar fashion, we can compute the expected utility of Gamble II as follows:

$$
\begin{aligned}
\mathrm{EU}(\mathrm{II}) & =\operatorname{Prob}(\mathrm{R}) \mathrm{U}(0)+\operatorname{Prob}(\mathrm{B}) \mathrm{U}(100)+\operatorname{Prob}(\mathrm{Y}) \mathrm{U}(0) \\
& =(1 / 3)(0)+(\rho)(1)+(1-\rho)(0)=\rho .
\end{aligned}
$$


Therefore, if Gamble I is preferred to II, then EU( I ) must be greater than EU( II) by view of the expected utility theory. So taking account of Eqs. (3) and (5), this is equivalent to saying that $1 / 3$ is greater than $\rho$. In other words, we have derived the following equivalent relation:

$$
\text { I is preferred to II } \Leftrightarrow 1 / 3>\rho \text {. }
$$

Let us turn to comparison between Gambles III and IV. The expected utilities of those gambles are calculated as follows:

$$
\begin{aligned}
\mathrm{EU}(\mathrm{III}) & =\operatorname{Prob}(\mathrm{R}) \mathrm{U}(100)+\operatorname{Prob}(\mathrm{B}) \mathrm{U}(0)+\operatorname{Prob}(\mathrm{Y}) \mathrm{U}(100) \\
& =(1 / 3)(1)+(\rho)(0)+(2 / 3-\rho)(1)=1^{-} \rho \\
\mathrm{EU}(\mathrm{IV}) & =\operatorname{Prob}(\mathrm{R}) \mathrm{U}(0)+\operatorname{Prob}(\mathrm{B}) \mathrm{U}(100)+\operatorname{Prob}(\mathrm{Y}) \mathrm{U}(100) \\
& =(1 / 3)(0)+(\rho)(1)+(2 / 3-\rho)(1)=2 / 3 .
\end{aligned}
$$

Hence, we find the following sequence of equivalent relations:

$$
\begin{aligned}
\text { IV is preferred to III } & \Leftrightarrow \mathrm{EU}(\mathrm{IV})>\mathrm{EU}(\mathrm{III}) \\
& \Leftrightarrow 2 / 3>1^{-} \rho \\
& \Leftrightarrow \rho>1 / 3 .
\end{aligned}
$$

Apparently, the two equivalent relations (6) and (9) are not compatible! This is really the essence of the famous Ellsberg paradox. In order to resolve the paradox, the first thing we should do is to seek very nice ways to get rid of the traditional expected utility theory.

\section{3-3. Alternative Ways to Resolve Ellsberg's Paradox}

Generally speaking, any kind of paradox would be a challenge to any intellectual person. In historical perspective, there have been several attempts to solve Ellsberg's paradox. Although Ellsberg (1960, 1961) himself attempted to propose his own solution, it is quite unfortunate that it has not been well-received and almost forgotten.

In our opinion, possibly the simplest solution is conceivable if Keynes's half-forgotten analysis of interval estimate technique is adopted here. ${ }^{6)}$

Keynes once remarked :

\footnotetext{
"The sphere of inexact numerical comparison is not quite so limited. Many probabilities, which
} 
are incapable of numerical measurement, can be placed nevertheless between numerical limits. And by taking particular non-numerical probabilities as standards a great number of comparisons or approximate measurements become possible." (Keynes, 1921, p.160)

Interval-valued probability, or simply interval probability, has not been a foreign idea to Keynes: and indeed, much interest has been revived by help of Brady (2004). As was seen above, Keynes argues that many probabilities, which are incapable of numerical measurement, can be placed nevertheless between numerical limits. Let us consider the interval probability of the form $[\alpha, \beta]$, with $\alpha$ and $\beta$ being its lower and upper limits. If we take account of the "weight of argument" a la Keynes, the weight Wght( $\cdot)$ of the argument of the interval $[\alpha, \beta]$ should be less that the "point probability" $\operatorname{Prob}(\cdot)$ of the mean $(\alpha+\beta) / 2$, so that we have

$$
\operatorname{Wght}([\alpha, \beta])<\operatorname{Prob}((\alpha+\beta) / 2) \text {. }
$$

Besides, without loss of generality, let us assume again that $\mathrm{U}(100)=1$ and $\mathrm{U}(0)=$ 0 . Then taking account of the interval probability argument, the weighted value of Gamble I is calculated as follows:

$$
\begin{aligned}
\mathrm{WV}(\mathrm{I}) & =\mathrm{Wght}(\mathrm{R}) \mathrm{U}(100)+\mathrm{Wght}(\mathrm{B} \text { or } \mathrm{Y}) \mathrm{U}(0) \\
& =\operatorname{Prob}(\mathrm{R}) \mathrm{U}(100)+\operatorname{Prob}(\mathrm{B} \text { or } \mathrm{Y}) \mathrm{U}(0) \\
& =(1 / 3)(1)+(2 / 3)(0)=1 / 3
\end{aligned}
$$

In an analogous way, the weighted value of Gamble II is computed as follows:

$$
\begin{aligned}
\mathrm{WV}(\mathrm{II}) & =\operatorname{Wght}(\mathrm{R}) \mathrm{U}(0)+\operatorname{Wght}(\mathrm{B}) \mathrm{U}(100)+\operatorname{Wght}(\mathrm{Y}) \mathrm{U}(0) \\
& =\operatorname{Prob}(\mathrm{R}) \mathrm{U}(0)+\operatorname{Wght}([0,2 / 3]) \mathrm{U}(100)+\operatorname{Wght}([0,2 / 3]) \mathrm{U}(0) \\
& =(1 / 3)(0)+\operatorname{Wght}([0,2 / 3])(1)+\operatorname{Wght}([0,2 / 3])(0) \\
& =\operatorname{Wght}([0,2 / 3]) .
\end{aligned}
$$

Hence the assertion that Gamble I is preferred to II means that $1 / 3$ is greater than Wght $([0,2 / 3])$, which tells us the gambler's "ambiguity aversion" a la Ellsberg. Summing up, we have thus obtained the following sequence of equivalent relations:

$$
\begin{aligned}
\text { I is preferred to II } & \Leftrightarrow \mathrm{WV}(\mathrm{I})>\mathrm{WV}(\mathrm{II}) \\
& \Leftrightarrow 1 / 3>\operatorname{Wght}([0,2 / 3]) .
\end{aligned}
$$


Likewise, the weighted values of Gambles III and IVare computed as follows:

$$
\begin{aligned}
\mathrm{WV}(\mathrm{III}) & =\operatorname{Wght}(\mathrm{R}) \mathrm{U}(100)+\operatorname{Wght}(\mathrm{B}) \mathrm{U}(0)+\operatorname{Wght}(\mathrm{Y}) \mathrm{U}(100) \\
& =\operatorname{Prob}(\mathrm{R}) \mathrm{U}(100)+\operatorname{Wght}([0,2 / 3)]) \mathrm{U}(0)+\operatorname{Wght}([0,2 / 3]) \mathrm{U}(100) \\
& =(1 / 3)(1)+\operatorname{Wght}([0,2 / 3])(0)+\operatorname{Wght}([0,2 / 3])(1) \\
& =1 / 3+\operatorname{Wght}([0,2 / 3]) ; \\
\mathrm{WV}(\mathrm{IV}) & =\operatorname{Wght}(\mathrm{R}) \mathrm{U}(0)+\operatorname{Wght}(\mathrm{B} \text { or } \mathrm{Y}) \mathrm{U}(100) \\
& =\operatorname{Prob}(\mathrm{R}) \mathrm{U}(0)+\operatorname{Prob}(\mathrm{B} \text { or } \mathrm{Y}) \mathrm{U}(100) \\
& =(1 / 3) \mathrm{U}(0)+(2 / 3)(1)=2 / 3 .
\end{aligned}
$$

Therefore we can obtain the following sequence of equivalent relations:

$$
\begin{aligned}
\text { IV is preferred to III } & \Leftrightarrow \mathrm{WV}(\mathrm{IV})>\mathrm{WV}(\mathrm{III}) \\
& \Leftrightarrow 2 / 3>1 / 3+\mathrm{Wght}([0,2 / 3]) \\
& \Leftrightarrow 1 / 3>\operatorname{Wght}([0,2 / 3]) .
\end{aligned}
$$

Very remarkably, this equivalent relation (16) is exactly as the same as the one (13). There exist no contradictions whatever if people prefer I to II but IV to III. Thus Ellsberg's paradox is now successfully resolved!

Although we think that the interval probability approach aforementioned is simple and powerful enough, it is also true that there has recently emerged mathematically minded people who have taken a more ambitious and sophisticated approach to resolution of Ellsberg 's paradox. Nishimura and Ozaki (2017), both ambitious Japanese mathematical economists, are among those people who have dared to make full use of Choquet integral and other highly advanced mathematical tools.

Following Nishimura and Ozaki, Let us define the set function $\Theta(\cdot)$ - especially named "probability capacity function"- as is indicated in Fig. 3. In view of the set of three colors, $\Sigma=\{\mathrm{R}, \mathrm{B}, \mathrm{Y}\}$, let us think of the set of all subsets of $\Sigma$ as the domain of the function $\Theta$ :

The domain of $\Theta=2^{\Sigma}=\{\phi,\{R\},\{B\},\{Y\},\{R, B\},\{R, Y\},\{B, Y\},\{R, B, Y\}\}$.

Thus $\Theta$ is a set-to-point mapping from the domain indicated by (17) into the range given by the unit interval $[0,1]$ such that $\Theta(\phi)=0, \Theta(\{R\})=1 / 9, \Theta(\{B\})=1 / 9, \Theta$ $(\{\mathrm{Y}\})=1 / 9, \Theta(\{\mathrm{R}, \mathrm{B}\})=4 / 9, \Theta(\{\mathrm{R}, \mathrm{Y}\})=4 / 9, \Theta(\{\mathrm{B}, \mathrm{Y}\})=2 / 3$ and $\Theta(\{\mathrm{R}, \mathrm{B}, \mathrm{Y}))=1 . \quad$ It is noted 


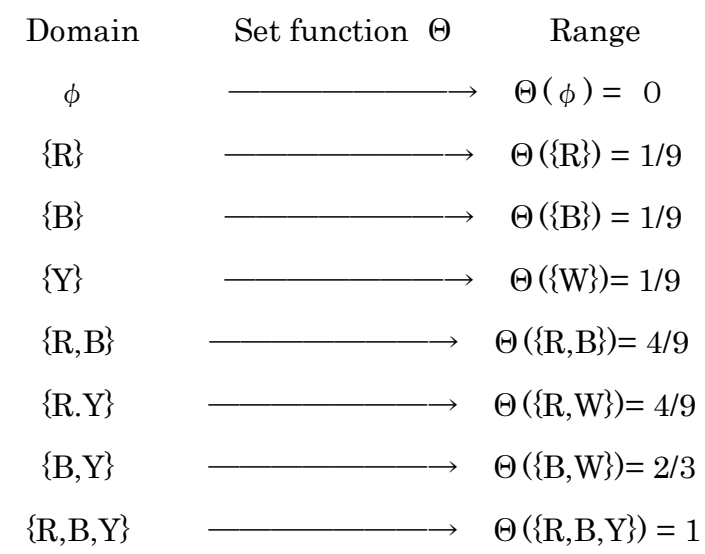

Fig. 3 Ellsberg's paradox reconsidered: a highly mathematical approach by means of the Choquet expected utility

here that in contrast to probability function $\operatorname{Prob}(\cdot)$, the newly-defined capacity function $\Theta(\cdot)$ does not satisfy the additivity property: for instance, $\Theta(\{R\})+\Theta(\{B\})=2 / 9<$ $4 / 9=\Theta(\{\mathrm{R}, \mathrm{B}\})$. The Chequet expected utilities of Gambles I and II above are calculated as follows:

$$
\begin{aligned}
\operatorname{CEU}(\mathrm{I}) & =\Theta(\{\mathrm{R}\}) \mathrm{U}(100)+\Theta(\{\mathrm{B}, \mathrm{Y}\}) \mathrm{U}(0) \\
& =(1 / 3)(1)+(2 / 3)(0)=1 / 3 ; \\
\mathrm{CEU}(\mathrm{II}) & =\Theta(\{\mathrm{R}\}) \mathrm{U}(0)+\Theta(\{\mathrm{B}\}) \mathrm{U}(100)+\Theta(\mathrm{Y}) \mathrm{U}(0) \\
& =(1 / 3)(0)+(1 / 9)(1)+(1 / 9)(0)=1 / 9 .
\end{aligned}
$$

According to the Chequet expected utility, the assertion that I is preferred to II means that CEU(I) is greater than CEU(II). This must be true since $1 / 3$ is surely greater than 1/9. Likewise, the Chequet expected utilities of Gamble III and IV are computed as follows:

$$
\begin{aligned}
\mathrm{CEU}(\mathrm{III}) & =\Theta(\{\mathrm{R}\}) \mathrm{U}(100)+\Theta(\{\mathrm{B}\}) \mathrm{U}(0)+\Theta(\{\mathrm{Y}\}) \mathrm{U}(100) \\
& =(1 / 3)(1)+(1 / 9)(0)+(1 / 9)(1)=1 / 3+1 / 9: \\
\mathrm{CEU}(\mathrm{IV}) & =\Theta(\{\mathrm{R}\}) \mathrm{U}(0)+\Theta(\{\mathrm{B}, \mathrm{Y}\}) \mathrm{U}(100) \\
& =(1 / 3)(0)+(2 / 3)(1)=2 / 3 .
\end{aligned}
$$


Consequently, the assertion that IV is preferred to III is equivalent to saying that as is expected, $2 / 3$ is greater than the sum of $1 / 3$ and $1 / 9$. Thus, relying on the Chequet expected utility theory, Nishimura and Ozaki have found their own way to solve Ellsberg's paradox.

As common sense experience tell us, there are surely many routes available to clime the mountaintop! One simple and reasonable route is the interval probability approach which was originally promoted by Keynes himself but later almost forgotten until it was rediscovered by Brady (2004). Another mathematically sophisticated route would be the Chequet expected utility approach which was initially taken on the base of Chequet integral, and recently developed by Nishimura and Ozaki (2017) for resolution of Ellsberg's paradox. 7)

We would like to stick to the common sense principle "the simpler, the better." Hopefully, a simpler approach could appeal to a wider range of audience.

\section{Concluding Remarks: Econs versus Humans}

In the above, we have intensively discussed the life and work of Daniel Ellsberg, with special reference to J.M. Keynes and F.H. Knight, the two superstars in the economics of uncertainty. As repeatedly mentioned, Ellsberg seems to be a man in paradox. Although he was the first man who pointed out the Ellsberg's paradox in the world of ambiguity, his academic results was destined to be forgotten because of his involvement in the political Pentagon Papers scandal. He is immortal, however; he will constantly be shining in the 21 st century.

In the light of economic history, we think that behind Ellsberg's personal struggle, there lies the academic struggle between "Econs" and "Humans." According to Richard H. Thaler (2015), a respected representative of our Rochester graduates, many standard models tend to use a fictional creature called homo economicus, or simply Econs. Econs are a sort of "rational fools" a la Amartia Sen (1987) in the sense that they rationally choose goods by optimizing their utilities, and have always rational expectations about market equilibriums. Although the traditional expected utility model is an extension of the standard rational model to the world of risk and uncertainty, its basic structure remains the same as before. In our opinion, a more mathematically sophisticated model using Choquet integral seems to essentially rely on the assumption of Econs.

In contrast, Humans are just human beings - homo sapiens. Compared with fictional Econs, Humans do a lot of misbehaving, implying that economic models lead to 
a lot of bad predictions. Humans are supposed to have a lot of non-rational feelings such as envy, hatred, optimism, pessimism, sympathy, compassion and the like. In the world where many Humans live, the traditional economic theory is far from satisfactory. We need to establish a more comprehensive model of human behavior including a variety of complicated psychologies. For instance, a nice bridge between economic theory and economic psychology must urgently be built.

In the above, we have sometimes introduced highly mathematical tools. It is recalled that Albert Einstein, probably the greatest scientist of the 20th century, once talked about his own philosophy of science:

"I have little patience with scientists who take a board of wood, look for its thinnest part, and drill a great number of holes where drilling is easy." (Albert Einstein, quoted by Phillip Frank, 1949)

In the real world, we are exposed to various temptations for easy going lives. So it would be a sad fact that we have a tendency to drill a great number of holes on a board of wood where drilling is rather easy. However, we have to take a very broad view of the wood without looking at only small trees. We are really Humans rather than Econs ! In order to further develop decision making under ambiguity, it is necessary to have the second Ellsberg or like in not a distant future.

\section{References}

Akerlof, G.A. and Shiller, R.J. (2009) Animal spirits: how human psychology drives the economy, and why it matters for global capitalism, Princeton University Press.

Arrow, K.J. (1951)"Alternative approaches to theory of choice in risk-taking situations, " Econometrica, 19, 404-437. Contained in Arrow (1970), Chapter 1.

Arrow, K.J. (1970) Essays in the theory of risk-bearing, North Holland.

Arrow, K.J. and Hahn, E.H. (1971) General Competitive Analysis, Holden-Day, San Francisco.

Bernoulli, Daniel (1738), "Specimen theorie novae de mensura sortis," Commentarii Academiae Scientiarum Imperialis Petropolitanae, Tomus V (Papers of the Imperial Academy of Sciences in Petersburg, Vol. 1), pp.175-195; translated by Louise Sommer, "Exposition of a new theory of the measurement of risk, Econometrica, Vol. 22, 1954, pp.23-36.

Brady, M.E. (2004) J.M. Keynes' theory of decision making, induction, and analogy: the role of interval valued probability in his approach, Xlibris Corporation, Illinois.

Boyd, R. (1997) "New introduction to the transaction edition" for F.H. Knight (1935) The Ethics of 


\section{Competition.}

Ellsberg, Daniel (1961) "Risk, ambiguity and the Savage axioms," Quarterly Journal of Economics, 75(4): 643-669.

Ellsberg, Daniel $(1962,2001)$ Risk, ambiguity and decision, London \& New York: Routledge.

Ellsberg, Daniel (2002) Secrets: a memoir of Vietnam and the Pentagon papers.

Emmett, R.B. (1999) Selected essays by Frank H. Knight, Volume One, University of Chicago Press.

Emmett, R.B. (1999) Selected essays by Frank H. Knight, Volume Two, University of Chicago Press.

Frank, Phillip (1949) "Einstein's Philosophy of Science, " Reviews of Modern Physics, 21-3.

Gilboa, I. and Schmeidler, D. (1989) "Maxmin expected utility with non-unique prior," Journal of Mathematical Economics, 18, pp.141-153.

Hicks, J. R. (1979) Causality in economics, Basic Blackell, Oxford.

Levi, I. (2001) "Introduction to Risk, Ambiguity and Decision," contained in Ellsberg (2001), pp. ix-xxxvii.

Keynes, J.M. (1921) A treatise on probability, Macmillan, London.

Keynes, J.M. (1936) The general theory of employment, interest and money, Macmillan, London.

Keynes, J.M. (1937) "The general theory of employment," Quarterly Journal of Economics 51(2), pp. 209-223.

Knight, F.H. (1921) Risk, uncertainty and profit, University of Chicago Press.

Knight, F.H. (1951) "The role of principles in economics and politics," American Economic Review, 41, March 1951, pp.1-29.

Nishimura, G.K. and Ozaki, H. (2017) Economics of Pessimism and Optimism: Theory of Knightian Uncertainty and Its Applications, Springer Japan

Sakai, Y. (2015) J.M. Keynes versus F.H. Knight, Minerva Publishing Company, Kyoto, in Japanese.

Sakai, Y. (2016) "J.M. Keynes on probability versus F.H. Knight on uncertainty: reflections on the miracle year of 1921," Evolutionary and Institutional Economics Review, 13(1), 1-21.

Schmeidler, D. (1989) Subjective probability and expected utility without additivity, Econometrica、57, pp. 571-587.

Skidelsky, R. (2009) Keynes: the return of the master, Public Affairs, New York.

Taleb, N. (2007) The black swan: the impact of the highly improbable, Allen Lane.

Thaler, R.H. (2015) Misbehaving: The Making of Behavioral Economics, Norton, New York.

Zappia, C. (2016) "Daniel Ellsberg and the Validation of Normative Propositions,"

Economia, 6-1, 57-79. 


\section{Endnotes}

* Financial support from the Japanese Ministry of Education, Culture, Sports, Science and Technology through Grant-in-Aid for Scientific Research (C) No. 16K03837 is gratefully acknowledged.

1) In retrospect, the 1960 s were truly turbulent years. While the Vietnam war was raging in Indochina, many young men and hippies in the U.S. and Japan were involved in social protest movements. So many scandals such as the Pentagon paper scandal and the Watergate scandal took place, eventually leading to the resignation of Richard Nixon, the then American President.

2) For details on Keynes versus Knight, see Sakai (2015). The writing of an English enlarged version is now in progress and will be finished in 2019 .

3) Skidelsky has enthusiastically argued that "the economics of John Maynard Keynes is back in fashion. The guardian of free-market orthodoxy the Wall Street Journal devoted a full page spread to him on 8 January 2009. The reason is obvious. The global economy is slumping; 'stimulus packages' are all the rage." (Skidelsky, 2009, Preface, page xi) It seems that we are now living in the second Age of Keynes.

4) For details of the economics of Knight, see Emmett (1999a,1999b) and Boyd (1997).

5) Although Arrow described his strong skepticism about Knightian uncertainty, it would sound rather strange that Arrow's comment on Keynesian uncertainty was not so critical. In fact, in Arrow and Hahn (1971), Arrow was so kind to discuss the position of the Keynesian model in relation to general competitive model.

6) It is recalled that usefulness of the interval probability approach was later advocated by Hicks (1979), an outstanding Keynesian economist.

7) Gustave Choquet (1915-2006) is a contemporary French mathematician. His contributions include work in functional analysis, potential theory, and measure theory. He is well-known for creating Choquet integral and Choquet theory. Choquet integral may be regarded as an extension of Lebesgue integral, which was created by Henri-Léon Lebesgue (1875-1941), another famed French mathematician. Although Choquet integral per se belongs to a highly advanced branch of mathematics, it has recently been applied to economic theory by Schmeidler (1989), Giboa \& Schmeidler (1989), and Nishimura \& Ozaki (2017). We have bear in mind, however, that there should be an insurmountable trade-off between intuitive simplicity and mathematical complexity. 